\title{
Avaliação clínica, laboratorial e ultrassonográfica de felinos com doença do trato urinário inferior
}

\section{Clinical, laboratory and ultrassonography evaluation feline with lower urinary tract disease}

\author{
Gisele Salengue Martins ${ }^{1}$; Andresa de Cassia Martini²; Yara Silva Meirelles²; \\ Valéria Dutra3; Pedro Eduardo Brandini Nespóli3; ${ }^{3}$ Adriane Jorge Mendonça ${ }^{3}$; \\ Mariana de Medeiros Torres ${ }^{4}$; Larissa Gaeta ${ }^{5}$; Geovanna Barreira Monteiro ${ }^{6}$; \\ Joadil Abreu ${ }^{3}$; Valeria Régia Franco Sousa ${ }^{3 *}$
}

\section{Resumo}

As Doenças do Trato Urinário Inferior Felino (DTUIF) são frequentes na rotina clínica desta espécie, é decorrente de diversos processos mórbidos caracterizados por hematúria, disúria, polaciúria, estrangúria, periúria e obstrução uretral, que afetam principalmente felinos sedentários, de vivência intradomiciliar e com baixa ingestão de água. Com o objetivo de verificar as principais alterações clínicas, laboratoriais e ultrassonográficas nos casos de DTUIF, foram examinados 26 felinos no Hospital Veterinário da UFMT, sendo, 16 com DTUIF e dez hígidos, notando-se que todos os animais doentes apresentaram azotemia, valor médio da concentração sérica de cálcio total diminuído e elevação na concentração sérica de fósforo. Crescimento bacteriano foi observado em um terço dos casos, sendo três possivelmente decorrentes de cateterização vesical, já que eram casos recidivantes. Os achados ultrassonográficos foram compatíveis com quadros de obstrução, tais como: distensão acentuada da vesícula urinária e debris em suspensão, dilatação de ureteres e uretra.

Palavras-chave: Doença do trato urinário inferior, felinos, azotemia, ultrassonografia

\begin{abstract}
The Lower Urinary Tract Disease Feline (FLUTD) are frequent in clinical routine of this species is due to various disease processes characterized by hematuria, dysuria, urinary frequency, strangury, periuria and urethral obstruction, affecting mainly sedentary cats, living in the home and with low intake of water. In order to check the main clinical, laboratory and ultrasound in cases of FLUTD, 26 cats were available at the Veterinary Hospital of UFMT being 16 with FLUTD and ten healthy, noting that all the sick animals had azotemia, average of serum total calcium decreased and elevation in serum phosphorus. Bacterial growth observed in one third of cases, three possibly due to bladder catheterization, as were recurrent cases. The sonographic findings were compatible with frames of obstruction, such as severe distension of the urinary bladder and debris in suspension, dilated ureters and urethra.
\end{abstract}

Key words: Lower urinary tract disease, feline, azotemia, ultrasound

\footnotetext{
${ }^{1}$ Médico Veterinário Residente Universidade Federal de Mato Grosso, UFMT, Cuiabá, MT. E-mail: salengue@gmail.com

${ }^{2}$ Discentes de Mestrado, UFMT, Cuiabá, MT. E-mail: andresa.martini@hotmail.com; yarameireles@gmail.com

${ }^{3}$ Profs. da UFMT, Cuiabá, MT. E-mail: valdutra@ufmt.br; nespolipb@gmail.com; adrianejm@ufmt.br; joadil@terra.com.br; regia@ufmt.br

${ }^{4}$ Discente de Doutorado, UFMT, Cuiabá, MT. E-mail:marys_torres@htomail.com

${ }^{5}$ Graduado, UFMT, Cuiabá, MT. E-mail:lara.gaeta@hotmail.com

${ }^{6}$ Médico Veterinário Residente, UFMT, Cuiabá, MT. E-mail: monteiro_nana@hotmail.com

* Autor para correspondência
} 
As Doenças do Trato Urinário Inferior Felino (DTUIF) é um dos diagnósticos mais comuns na medicina felina, e resultam de infecções bacterianas, fúngicas ou parasitárias das vias urinárias, de anormalidades anatômicas das vias urinárias, de diferentes tipos de urólitos e tampões uretrais, de neoplasias ou de causas traumáticas, neurogênicas ou iatrogênicas. Entretanto, em 50 a $65 \%$ dos animais acometidos não é possível identificar a etiologia com precisão, classificando-a como cistite idiopática, o que torna um desafio diagnóstico e terapêutico ao clínico veterinário, já que a etiologia pode ser multifatorial e complexa (KRUGER; OSBORNE; LULICH, 2008).

Historicamente, a taxa de incidência da DTUIF tem registrado valores $<1 \%$ nos EUA e no Reino Unido. A cistite idiopática (CIF) é indiscutivelmente a causa mais comum de DTUIF mundialmente em gatos com idades entre um e dez anos (HOUSTON, 2007), e parece ser mediada por neurotransmissores liberados de fibras nervosas aferentes sensitivas (KRUGER; OSBORNE; LULICH, 2008). A urolitíase constitui a segunda causa de DTUIF e é responsável por 13 a $28 \%$ das consultas dos gatos com doença do trato urinário inferior (HOUSTON, 2007).

Em relação a formação de urólitos acreditavase que era induzida por dietas secas industrializadas ricas em cálcio, magnésio e fosfatos (RECHE JÚNIOR; HAGIWARA; MAMIZUKA, 1998; SEGEV et al., 2011). Atualmente, para evitar a precipitação de cristais e formação de cálculos urinários de estruvita, a manutenção de um pH urinário ácido é mais importante que o controle da ingestão de magnésio ou fosfatos, uma vez que esses cristais têm sua solubilidade diminuída em $\mathrm{pH}>6,45$ (RECHE JÚNIOR; HAGIWARA; MAMIZUKA, 1998). No entanto, a maioria dos casos de obstrução uretral nos gatos está relacionada aos tampões uretrais que geralmente são compostos por uma combinação de material protéico (mucoproteínas de Tam Horsfall) e cristais, mas, ocasionalmente, os tampões são formados de matriz orgânica, células sanguíneas ou agregados de cristais minerais (SEGEV et al., 2011).

Em grande parte, a DTUIF acomete gatos machos, obesos, sedentários, alimentados com ração seca, de vivência intradomiciliar, onde convivem com outros animais e com hábito de beber água somente em bebedouro. Foi demonstrado que, em comparação com os gatos domésticos de pelo curto, o risco é menor nos siameses e maiores nos persas, decorrente, provavelmente, de características raciais, como a letargia e a obesidade dos gatos persas (KING, 2005). Outro fator que predispõe a DTUIF é o estresse, semelhantemente a cistite intersticial humana (CIH), a CIF possui base neuroimunoendócrina. Este fato relaciona também a recidiva em 35 a 50\% dos felinos (GIOVANINNI; PIAI, 2010).

Os gatos acometidos por DTUIF apresentam hematúria, polaciúria, disúria ou estrangúria, distensão vesical e sinais de uremia, como vômitos, anorexia, letargia, fraqueza e anúria (SAEVIK et al., 2011). A urinálise demonstra intensa hematúria, principalmente pela distensão vesical e pelo processo inflamatório, variação no $\mathrm{pH}$ urinário, e presença de células inflamatórias, bactérias e/ou cristais (HOUSTON, 2007). No decorrer do quadro obstrutivo, estarão aumentados os valores séricos de creatinina e uréia. Em alguns animais pode estar presente acidose metabólica (OSBORNE et al., 2004). A urocultura deve ser realizada para descartar ou identificar infecção do trato urinário nos felinos com suspeita de doença isolada ou associada com estruvita, apesar de dificilmente ocorrer infecção no primeiro episódio (RECHE JÚNIOR, 2005).

A ultrassonografia que tem boa acurácia no diagnóstico de cálculos vesicais e boa aplicabilidade na diferenciação de dilatações pélvicas também tem a vantagem de verificar a integridade do trato urinário, e a presença de tampões e urólitos na vesícula urinária que possam migrar para a uretra, e desta forma perpetuar a obstrução intraluminal (JARRETTA, 2009). 
O prognóstico depende do tempo de obstrução, de complicações e de sua gravidade. Azotemia e as consequências da insuficiência renal são os maiores fatores de óbito entre os felinos acometidos (RECHE JÚNIOR; HAGIWARA; MAMIZUKA, 1998). O tratamento consiste na restauração de uma uretra patente, viabilizando a excreção urinária, e a correção das alterações sistêmicas com reposição hidroeletrolítica (OSBORNE et al., 2004).

Este trabalho se propôs avaliar as alterações clínicas, laboratoriais e ultrassonográficas observadas em felinos com doença do trato urinário inferior (DTUIF), atendidos na Clínica Médica de Pequenos Animais do Hospital Veterinário da Universidade Federal de Mato Grosso (HOVET UFMT).

No decorrer do ano de 2010, com o consentimento do proprietário, foram examinados 26 felinos, sendo divididos em dois grupos: dezesseis com DTUIF (grupo de estudo-G1) e dez saudáveis (grupo controle-G2) no setor de Clínica Médica do Hospital Veterinário da Universidade Federal de Mato Grosso (HOVET-UFMT), visando estimar a prevalência de DTUIF.

$\mathrm{Na}$ análise clínica de felinos com DTUIF, após a identificação dos animais, procurou-se relacionar alguns fatores como, sedentarismo, dieta alimentar, ingestão de água, ambiente, micção, vocalização, caixa de areia, recorrência e tratamentos anteriores. Já no exame físico, realizou-se a avaliação geral, assim como do sistema urinário.

As análises hematológicas, bioquímicas séricas e urinárias foram realizadas no Laboratório de Patologia Clínica do Hospital Veterinário da UFMT. Duas amostras de sangue foram obtidas por venopunção jugular, sendo uma com EDTA para hematologia processada de acordo com Jain (1993), e outra sem anticoagulante para obtenção do soro sendo processado pelo método cinético através de analisador bioquímico semi-automático (SB 190 CELM ${ }^{\circledR}$ ) com o uso de kits comerciais (uréia, creatinina, cálcio e fósforo).
Assepticamente, as amostras de urina foram colhidas por cistocentese e imediatamente processadas segundo Meyer, Coles e Rich (1995) para urinálise, sendo também realizada urocultura. Após a identificação e quantificação dos agentes microbiológicos isolados, foi realizado o antibiograma.

Após anestesia dissociativa, com $8 \mathrm{mg} / \mathrm{kg}$ de cloridrato de cetamina (Syntec ${ }^{\circledR}$ ) e $4 \mathrm{mg} / \mathrm{kg}$ de midazolam, por via intramuscular dos animais com DTUIF e dos sem alterações clínicas, foi procedida a avalição ultrassonográfica (Esaote; modelo MYLAB ${ }^{\text {TM }}$ FIVE; probes micro-convexo 5-8 $\mathrm{MHz}$ e linear 3,5-10 MHz) do sistema urinário verificando o tamanho, formato, localização dos rins, ureteres e bexiga (NYLAND et al., 2005).

Os dados foram analisados de forma descritiva e pelo teste $t$ de Student $(\mathrm{P}<0,05)$, sendo as análises estatísticas realizadas através do programa estatístico SAEG versão 5.0 (RIBEIRO JÚNIOR, 2001).

No período analisado, foram atendidos 316 felinos, sendo a prevalência de DTUIF de 6,3\% (20). Destes, quinze felinos $(93,7 \%)$ não possuíam definição racial e $5(31,2 \%)$ eram castrados. No entanto, em apenas dezesseis animais houve consentimento do proprietário para realização das análises laboratoriais e ultrassonográficas. Neste grupo, apenas um $(6,2 \%)$ não tinha acesso à rua, cinco felinos $(31,2 \%)$ faziam uso da caixa de areia, enquanto a maioria $(93,8 \%)$ dos felinos se alimentava de ração seca. De acordo com Segev et al. (2011) a ingestão de formulações secas podem ser um fator de risco para ocorrência de DTUIF.

A prevalência de machos com DTUIF foi de $80 \%$ (16) enquanto que nas fêmeas foi de $20 \%$ (4), segundo Osborne et al. (2004), machos e fêmeas têm risco similar para as formas não obstrutivas da doença, porém a obstrução uretral ocorre mais comumente em machos, devido a menor elasticidade, comprimento e diâmetro da uretra quando comparada à uretra das fêmeas. As 
fêmeas são mais acometidas pela cistite intersticial (OSBORNE et al., 2004), que é uma forma não obstrutiva da doença, apesar de não apresentarem características clínicas tão evidentes como os machos, dificultando a percepção da doença pelo proprietário e o diagnóstico do médico veterinário.

Em relação ao peso corpóreo, não houve diferença estatística entre os grupos, sendo o valor médio para os felinos doentes de $3,8 \mathrm{Kg}$. A idade dos animais acometidos variou entre sete meses e seis anos, sendo o valor médio de 37,2 meses. De acordo com Osborne et al. (2004), a DTUIF é mais comum em gatos com idade entre um e dez anos, com pico de ocorrência entre dois e seis anos e rara em animais com idade inferior a um ano. Dessa forma, os dados por nós obtidos se assemelham a literatura consultada.

Dentre os sinais clínicos averiguados em felinos com DTUIF, apatia, disúria, hematúria e estrangúria associada à polaciúria foram identificados em quatro, nove, quatorze e doze animais, respectivamente (SEGEV et al., 2011). Outro sinal incluiu vocalização que pode ser atribuído a dor ou mesmo, mudança no comportamento que são sinais apresentados antes de ocorrer a completa obstrução uretral caracterizando um grupo heterogêneo de distúrbios (HOUSTON, 2007).

$\mathrm{O}$ valor médio da temperatura retal foi de $37,4^{\circ} \mathrm{C}$ caracterizando hipotermia em nove felinos acometidos por DTUIF. Além de hipotermia, geralmente, os animais obstruídos por 24 a 36 horas apresentam outros sinais clínicos associados à azotemia pós-renal como vômito, anorexia, depressão, desidratação e até colapso. Alteração na frequência cardíaca foi identificada apenas em um animal, o qual apresentou bradicardia. Nesses pacientes, essa arritmia está associada à hipercalemia decorrente do acúmulo de toxinas urêmicas e desequilíbrios eletrolíticos e acidobásicos pela obstrução uretral ou uroabdômen que induzem a diminuição da taxa de filtração glomerular (SEGEV et al., 2011). A maioria dos felinos (12 de 16) acometidos apresentou taquipnéia. Segundo Horta (2006), a taquipnéia pode ser secundária a dor, estresse ou a acidose metabólica.

Em relação ao eritrograma, houve diferença significativa entre os grupos quanto ao valor médio resultante da contagem de hemácias. Apesar destes valores estarem dentro dos de normalidade, estavam próximos ao limítrofe superior no grupo com DTUIF condizente com o quadro de hemoconcentração resultante de desidratação por oligodipsia associada à perda de líquidos. Ao comparar os grupos, observou-se discreta leucocitose por neutrofilia e linfopenia nos animais com DTUIF. Houve diferença significativa quanto ao valor médio na contagem de neutrófilos, eosinófilos e linfócitos, sendo observado aumento do número dos neutrófilos e diminuição dos outros dois tipos celulares nos gatos afetados. Os resultados observados no leucograma dos animais com DTUIF podem ser resultantes do estresse gerado pela condição clínica dos mesmos ou uma resposta inflamatória a doença (HORTA, 2006).

De acordo com a tabela 1, a uréia nos felinos com DTUIF estava elevada de forma estatisticamente significativa, refletindo um comprometimento dos túbulos renais, pelo quadro obstrutivo ou pela azotemia pós-renal (OSBORNE et al., 2004), o que difere dos não acometidos, onde a elevação da uréia pode ser decorrente da dieta rica em proteínas (MEYER et al., 1995). 
Tabela 1. Valores bioquímicos séricos, de urinálise e hematológicos dos felinos com Doença do Trato Urinário Inferior (G1) e do Grupo Controle (G2).

\begin{tabular}{|c|c|c|c|c|}
\hline & \multicolumn{2}{|c|}{ Portadores de DTUIF } & \multicolumn{2}{|c|}{ Não Portadores de DTUIF } \\
\hline & Média & Desvio padrão & Média & Desvio padrão \\
\hline \multicolumn{5}{|l|}{ Bioquímica sérica } \\
\hline Ureia (mg/dL) & $198.18 \mathrm{a}$ & 143,75 & $57.5 \mathrm{~b}$ & 11,02 \\
\hline Creatinina (mg/dL) & $6.20 \mathrm{a}$ & 6,19 & $0.98 \mathrm{~b}$ & 0,30 \\
\hline Cálcio $(\mathrm{mg} / \mathrm{dL})$ & $9.36 \mathrm{~b}$ & 1,10 & $10.38 \mathrm{a}$ & 1,02 \\
\hline Fósforo (mg/dL) & $9.25^{\mathrm{a}}$ & 5,03 & $4.97 \mathrm{~b}$ & 1,10 \\
\hline \multicolumn{5}{|l|}{ Urinálise } \\
\hline Densidade urinária & $1035.75 \mathrm{~b}$ & 16,29 & $1077.6 \mathrm{a}$ & 11,50 \\
\hline $\mathrm{pH}$ & $6.96 \mathrm{a}$ & 0,80 & $5.65 \mathrm{~b}$ & 0,74 \\
\hline \multicolumn{5}{|l|}{ Valores hematológicos } \\
\hline Eritrócito $\left(10^{6} / \mathrm{mL}\right)$ & $8.15 \mathrm{a}$ & 2,00 & $6.66 \mathrm{~b}$ & 1,02 \\
\hline Hemoglobina (g/dL) & $12.79 \mathrm{a}$ & 3,25 & $10.14 \mathrm{~b}$ & 1,79 \\
\hline Hematócrito $(\%)$ & $39.5 \mathrm{a}$ & 8,76 & $31.8 \mathrm{~b}$ & 4,80 \\
\hline VGM (fL) & $48.93 \mathrm{a}$ & 6,90 & $47.74 \mathrm{a}$ & 0,38 \\
\hline $\mathrm{CHGM}(\mathrm{g} / \mathrm{dL})$ & $31.96 \mathrm{a}$ & 2,18 & $31.53 \mathrm{~b}$ & 1,94 \\
\hline Leucócito $\left(10^{3} / \mathrm{mm}^{3}\right)$ & $19.3 \mathrm{a}$ & 8,83 & $17.67 \mathrm{~b}$ & 12,88 \\
\hline Bastonete $\left(10^{3} / \mathrm{mm}^{3}\right)$ & $0.07 \mathrm{~b}$ & 0,27 & $0.08 \mathrm{a}$ & 0,20 \\
\hline Neutrófilo $\left(10^{3} / \mathrm{mm}^{3}\right)$ & $17.31 \mathrm{a}$ & 8,10 & $10.84 \mathrm{~b}$ & 5,50 \\
\hline Eosinófilo $\left(10^{3} / \mathrm{mm}^{3}\right)$ & $0.26 \mathrm{~b}$ & 0,38 & $0.9 \mathrm{a}$ & 0,64 \\
\hline Linfócito $\left(10^{3} / \mathrm{mm}^{3}\right)$ & $1.00 \mathrm{~b}$ & 0,77 & $2.03 \mathrm{a}$ & 1,01 \\
\hline Monócito $\left(10^{3} / \mathrm{mm}^{3}\right)$ & $0.64 \mathrm{a}$ & 0,85 & $0.96 \mathrm{a}$ & 0,84 \\
\hline Plaqueta $\left(10^{3} / \mathrm{mm}^{3}\right)$ & $311.87 \mathrm{a}$ & 69,37 & $353.2 \mathrm{a}$ & 157,46 \\
\hline Proteína $(\mathrm{g} / \mathrm{dL})$ & $7.46 \mathrm{a}$ & 0,96 & $7.24 \mathrm{a}$ & 0,86 \\
\hline
\end{tabular}

Médias na mesma linha seguidas por letras iguais indicam não haver diferença estatística significativa $(\mathrm{P}>0,05)$.

Fonte: Elaboração dos autores.

Hiperfosfatemia, que assim como a azotemia é causada pela diminuição da taxa de filtração glomerular e justifica-se pela fisiopatologia do processo (MEYER et al., 1995). Neste estudo o cálcio sérico estava reduzido no grupo de felinos com DTUIF em comparação com o grupo de felinos sadios, provavelmente como consequência do acúmulo de fósforo podendo servir como marcador indireto da intensidade da obstrução. A hipocalcemia pode exacerbar a cardiotoxicidade da hipercalemia, levando a morte (SEGEV et al., 2011).

Nos felinos com DTUIF a densidade urinária manteve-se dentro da normalidade em 12 (75\%) gatos sendo a média 1035, com tendência ao limítrofe inferior, e os outros quatro (25\%) apresentaram hipostenúria sugerindo uma doença renal. Já que a perda de habilidade para a concentração de urina é um dos primeiros sinais de doença tubular renal, além de refletir o estado de hidratação do animal. Adicionalmente, foi observado hematúria, em oito (50\%); proteinúria em todos felinos estudados acometidos, além de células renais. Achados que podem ser atribuídos ao processo inflamatório (cistite) e ao comprometimento renal secundário (MEYER et al., 1995). Células vesicais, pélvicas e tubulares renais foram visualizadas na análise de sedimento de oito (50\%) amostras, tanto como ovo de Capillaria sp em uma delas.

$\mathrm{O}$ pH urinário oscilou entre seis e oito com valor médio de 6,96 nos animais com DTUIF, considerado alcalino em relação aos valores de referência, pode ser atribuído ao estresse, à hiperventilação com concomitante aumento na eliminação renal de íon bicarbonato e à infecção urinária (RECHE 
JÚNIOR; HAGIWARA; MAMIZUKA, 1998). Em dois $(12,5 \%)$ gatos foram observadas a presença de cristais de estruvita que prevalecem em $\mathrm{pH}$ alcalino (acima de 6,4) (OSBORNE et al., 2004).

Na urocultura de seis $(37,5 \%)$ felinos com DTUIF foram detectados Staphylococcus intermedius (resistente a ampicilina, neomicina, penicilina e sulfonamidas), Staphylococcus aureus (resistente a ampicilina, penicilina, sulfonamidas) Bacillus sp, Corynebacterium sp e Streptococcus sp (resistente a neomicina e sulfonamidas). Três destes eram pacientes com recidiva de quadro clínico, podendo estar relacionada a cateterização uretral (RECHE JÚNIOR; HAGIWARA; MAMIZUKA, 1998; SEGEV et al., 2011). Segundo Reche Júnior (2005) a presença de Staphylococcus spp, Corynebacterium spp e Streptococcus spp estão relacionadas com quadros de insuficiência renal crônica, uretrostomia ou obstrução uretral.

Nos achados ultrassonográficos (Tabela 2), notouse que a córtex renal estava mais ecogênica em um felino $(6,25 \%)$, que pode ser observada em nefrite glomerular e intersticial ou de forma fisiológica em gatos hígidos obesos, sendo a diferenciação feita pela associação dos sinais clínicos e achados histopatológicos (SILVA; MAMPRIM; VULCANO, 2008). Todos os felinos estavam com distensão vesical acentuada, notou-se derrame peritoneal decorrente da cistocentese em um felino (6,25\%) (GIOVANINNI; PIAI, 2010), espessamento da parede vesical em outro $(6,25 \%)$ o que corrobora com a presença de inflamação vesical crônica. A cistite aguda pode não causar alterações de parede, mas se sangue, pus ou debris celulares estiverem presentes na urina, serão visibilizados como múltiplos ecos puntiformes em suspensão na urina normalmente anecogênica, sugerindo o diagnóstico em dois felinos onde a presença de estrutura hiperecóica situada no lúmen vesical, compatível com coágulo, foi observada (VAC, 2004). Dilatação de ureteres (ureter esquerdo $0,27 \mathrm{~cm}$ e ureter direito $0,6 \mathrm{~cm}$ ) foi visualizada em um felino (6,25\%). Normalmente os ureteres não são visibilizados ao ultrassom, somente são vistos quando estão dilatados por ectopias, neoplasias em bexiga, ureterite ou obstrução, resultando em hidronefrose (SILVA; MAMPRIM; VULCANO, 2008).

Tabela 2. Avaliação ultrassonográfica do trato urinário de felinos com e sem Doença do Trato Urinário Inferior (G1) e (G2).

\begin{tabular}{|c|c|c|c|c|c|}
\hline & & G1 & G2 & G1 & G2 \\
\hline & & Rim esquerdo & Rim esquerdo & Rim direito & Rim direito \\
\hline \multirow[t]{4}{*}{ Corte Longitudinal } & $\mathrm{CP}$ & $4.05 \mathrm{a}$ & $3.77 \mathrm{a}$ & $4.01 \mathrm{a}$ & $3.83 \mathrm{a}$ \\
\hline & $\mathrm{H}$ & $2.29 a$ & $2.22 \mathrm{a}$ & $2.41 \mathrm{a}$ & $1.93 \mathrm{a}$ \\
\hline & $\mathrm{CT}$ & $0.57 \mathrm{a}$ & $0.55 \mathrm{a}$ & $0.55 \mathrm{a}$ & $0.48 \mathrm{a}$ \\
\hline & MD & $0.49 a$ & $0.37 \mathrm{~b}$ & $0.49 \mathrm{a}$ & $0.41 \mathrm{a}$ \\
\hline \multirow[t]{2}{*}{ Corte Transversal } & $\mathrm{CP}$ & $2.74 \mathrm{a}$ & $2.49 \mathrm{a}$ & $2.77 \mathrm{a}$ & $2.64 \mathrm{a}$ \\
\hline & $\mathrm{H}$ & $2.40 \mathrm{a}$ & $2.05 \mathrm{a}$ & $2.35 \mathrm{a}$ & $1.98 \mathrm{a}$ \\
\hline Área & & $5.10 \mathrm{a}$ & $3.90 \mathrm{a}$ & $5.08 \mathrm{a}$ & $4.06 \mathrm{~b}$ \\
\hline
\end{tabular}

$\mathrm{CP}$ (comprimento); H (altura); CT (cortical); MD (medular); Médias seguidas de mesma letra não diferem do teste $\mathrm{t}(\mathrm{P}<0,05)$, avaliação em linha.

Fonte: Elaboração dos autores. 
Os felinos diagnosticados com DTUIF apresentaram sinais clínicos característicos, azotemia, diminuição na concentração sérica de cálcio contrapondo ao aumento de fósforo e infecção bacteriana principalmente nos casos recidivantes. No diagnóstico por imagem verificou-se dilatação ureteral, presença de debris na bexiga e alterações na ecogenicidade renal.

\section{Comitê de Ética e Biossegurança}

O projeto foi aprovado pelo CEPA sob o número 23108.014725/10-1.

\section{Referências}

GIOVANINNI, L. H.; PIAI, V. S. O uso da acupuntura no auxílio à terapia da doença idiopática do trato urinário inferior dos felinos. Ciência Rural, Santa Maria, v. 40, n. 3, p. 712-717, 2010.

HORTA, P. V. P. Alterações clínicas, laboratoriais e eletrocardiográficas em gatos com obstrução uretral. 2006. Dissertação (Mestrado em Clínica Veterinária) Curso de Pós-Graduação em Veterinária, Universidade de São Paulo, São Paulo.

HOUSTON, D. M. Epidemiologia da urolitíase felina. Veterinary Focus, Boulogne, v. 17, n. 1, p. 4-9, 2007.

JAIN, N. C. Essencials of veterinary hematology. Philadelphia: Lea e Febiger, 1993. 417 p.

JARRETTA, G. B. A utilização da ultrassonografia Doppler na avaliação renal de pequenos animais. 2009. Monografia (Diagnóstico por imagem em pequenos animais) - ANCLIVEPA, São Paulo.

KING, P. H. Controle dietético da LUTD. Revista Clínica Veterinária, São Paulo, v. 5, n. 55, p. 26-27, 2005.

KRUGER, J. M.; OSBORNE, C. A.; LULICH, J. P. Changing paradigms of feline idiopathic cystitis. Veterinary Clinics of North America: Small Animal Practice, Philadelphia, v. 39, n. 39, p. 15-40, 2008.
MEYER, D. J.; COLES, E. H.; RICH, L. J. Medicina de laboratório veterinária. São Paulo: Roca LTDA, 1995. $310 \mathrm{p}$.

NYLAND, T. G.; MATTOON, J. S.; HERRGESELL, E. J.; WISNER, E. R. Trato urinário. In: NYLAND, T. G.; MATTOON, J. S. Ultra-som diagnóstico em pequenos animais. São Paulo: Roca, 2005. p. 161-198.

OSBORNE, C. A.; KRUGER, J. M.; LULICH, J. P.; POLZIN, D. J.; LEKCHAROENSUK, C. Afecções do trato urinário inferior dos felinos. In: ETTINGER, S. J.; FELDMAN, E. C. Tratado de medicina interna veterinária: doenças do cão e do gato. Rio de Janeiro: Guanabara Koogan, 2004, p. 1802-1841.

RECHE JÚNIOR, A. A orbifloxacina no tratamento das cistites bacterianas em gatos domésticos. Ciência Rural, Santa Maria, v. 35, n. 6, p. 1325-1330, 2005.

RECHE JÚNIOR, A.; HAGIWARA, M. K.; MAMIZUKA, E. Estudo clínico da doença do trato urinário inferior em gatos domésticos de São Paulo. Brazilian Journal of Veterinary Research and Animal Science, São Paulo, v. 35, n. 2, p. 69-74, 1998.

RIBEIRO JÚNIOR, J. I. Análise estatística no SAEG. Viçosa: UFV. 2001. 301 p.

SAEVIK, B. K.; TRANGERUD, C.; OTTESEN, N.; SORUM, H.; EGGERTSDÓTTIR, A. V. Causes of lower urinary tract disease in Norwegian cats. Journal of Feline Medicine and Surgery, Vancouver, v. 13, n. 6, p. 410-417, 2011.

SEGEV, G.; LIVNE, H.; RANEN, E.; LAVY, E. Urethral obstruction in cats: predisposing factors, clinical, clinicopathological characteristics and prognosis. Journal of Feline Medicine and Surgery, Vancouver, v. 13, n. 2, p. 101-108, 2011.

SILVA, V. C.; MAMPRIM, M. J.; VULCANO, L. C. Ultra-sonografia no diagnóstico das doenças renais em pequenos animais. Revista Veterinária e Zootecnia, Botucatu, v. 15, n. 3, p. 435-444, 2008.

VAC, M. H. Sistema urinário: rins, ureteres, bexiga urinária e uretra. In: CARVALHO, C. F. Ultra-sonografia em pequenos animais. São Paulo: Roca, 2004. p. 111146. 
